\title{
Calling All American Physician Leaders
}

\author{
George D. Lundberg, MD
}

Stanford University, Los Gatos, CA, USA.

J Gen Intern Med 29(5):696-7

DOI: $10.1007 / \mathrm{s} 11606-014-2803-3$

(c) Society of General Internal Medicine 2014

$\mathrm{M}$ edicine has always been a business and a profession. Balance is the key. Throughout the developed world, medical care is primarily about health. Since the 1980s, medical care in America has increasingly become primarily about money. In the old days, diagnostic tests were few and use of clinical judgment was heavy. In the not so old days, laboratory testing became common, and reliance on clinical diagnostic acumen began to disappear. Today, medical capitalism reigns. Do as much and as many as you can, as you are permitted to, or can get away with; payment is for volume. The pendulum must swing. And swing it will.

Complaints about the level of spending for American health care have been around for at least a century. But complaints turned to concern in the 1980s and then to deep concern by 2000 . Except for a brief hiatus produced by managed care in the mid-1990s and the recent "great recession", the rate of inflation for American healthcare has been in the range of two to three times that of general inflation for as many years as I have been tracking it. Thus, the percentage of Gross Domestic Product (GDP) attributable to healthcare has risen from about $3 \%$ in 1929 to more than $17 \%$ in 2013. One could argue (or perhaps rationalize) that such spending is acceptable. After all, what could be more important than health? But that view comes a cropper when faced with the fact that no other developed country has experienced such huge growth in health spending; that American life expectancy at birth has not risen proportionately; that the US lags behind most other lesser spending developed countries on most health care quality measures; that US poverty rates have worsened and that poverty itself has been demonstrated to have a profoundly detrimental effect on health; and that education (amongst other essentials) has increasingly suffered from the siphon of the "American Medical Industrial Complex." The present course is clearly unsustainable.

The main drivers of healthcare cost inflation include: population growth; an aging population; new technology; promising new research results; excessive patient expectations to live "forever healthy"; medical advertising and marketing; supply-induced demand; the pharmaceutical and

Published online February 19, 2014 device industry; the information technology industry; community competition to provide the biggest and the best; financial conflicts of interest; lifestyle expectations of the healthcare workforce, especially physicians; the fee-forservice system that rewards volume of services rendered; general absence of cost transparency; wasteful administrative costs; overuse of diagnostic and therapeutic interventions often not based on sound evidence; the profit motive of shareholders of for-profit medical care entities; undetected medical and insurance fraud; excessive incomes of healthcare executives; the community dominance and influence of many healthcare entities as a local employer; inability of our culture to deal realistically with the cost/ benefit equation of end-of-life care; payment schemes that reward volume not value; a professional liability system that has for so long encouraged "defensive medicine" as to be seen by many as "normal"; and third-party payment that insulates most participants from the specific cost implications of most transactions.

This is a daunting list that explains rather well why the cost curve continues to rise. The American healthcare system has become a luxury ocean liner steered by and full of individuals happy with their economic good fortune. Every dollar that is not spent on health becomes a dollar taken from some American healthcare worker. If one accepts the notion that this situation must end, how could the country turn it around?

Is there a potential leadership role for physicians as responsible professionals and also as concerned citizens? I would say yes. As "learned professionals," I believe that it is the duty of American physicians and their organizations to lead this change. But is this even possible?

The slice of the American healthcare expenditure pie that goes for physician fees is only about $20 \%$. However, the percentage of American healthcare expenditures that are driven by physician decisions may approach $75 \%$. What (if any) lab tests to order, where and how frequently; what (if any) imaging procedures to obtain and where; what (if any) trade name (or generic) medications to prescribe; what (if any) patients should be hospitalized and for how long; which (if any) patients need be placed in an ICU and for how long; what (if any) surgical procedures need to be performed; where (if any) treatment should be given; whether to seek consultation, who, where, how many and how often? Yet, when asked in a survey research study what were the primary drivers of American health care costs, 
most physicians pointed the finger at others. ${ }^{1}$ While "guidelines" may compel certain physician decisions, physicians write the guidelines. Furthermore, physicians often do not follow guidelines; their behavior is largely determined by other factors.

Most laboratory and imaging tests that are done do not need to be done. The results are negative, normal, or unchanged from the prior test result. Since the 1980s, conventional wisdom has held that $25-50 \%$ of medical testing is inappropriate $^{2}$ and often leads to a cascade of more actions. ${ }^{3}$

What to do? Under the "Choosing Wisely" campaign and the Lown Foundation's "From Avoidable Care to Right Care" project, more than 60 medical societies have now identified over 200 medical actions that should be questioned, the elimination of which can provide lower costs and better quality care. The Society of General Internal Medicine (SGIM) is among the leaders of this movement. There are now myriad opportunities for general internists to take the lead in turning this out-of-control monster ship around, thereby rescuing not only our professionalism, but our country.

The article by Horn et al. in this issue of $\mathrm{JGIM}^{4}{ }^{4}$ reports the results of one recent attempt by one group of primary

\section{Table 1. A Proposed Method of Changing Physician Behavior}

Data and experience support that the best ways to change physician behavior regarding the ordering of diagnostic tests are:

1. Know the literature, have the data, and be certain that you know the right thing to do.

2. Convene (preferably under the roles of the organized medical staff) a small committee of leading respected physicians in the health care setting - those who know the most about the subject at issue. These physicians usually will not be department heads, but rather middlelevel active clinicians.

3. Achieve agreement with this group about what should be done based on available scientific evidence and the best expert clinical opinion.

4. Implement the changes administratively, without seeking broader agreement in advance.

5. Add a large dose of education in writing and in conferences about what was done, why this is best for patients and the institution, and how to adjust to the changes.

6. Be open to communication, complaints, letters, visits, telephone calls, and even insurrection.

7. Ride out the actions and overreactions, carefully sorting all objections and responding with adjustments, usually minor, to valid complaints

8. Enjoy the success of providing better, cheaper, faster, more effective diagnostic services in the best interest of patients, physicians, the public, the institution, and the payer. care physicians in one state (Massachusetts) to learn whether the provision of one set of cost-charge data (Medicare payment rates per test) on two groups of clinical laboratory tests, all other factors remaining relatively equal, would have any effect on the frequency with which these tests were ordered. They found that, in fact, compared to a control group, some physicians in the intervention group did order somewhat fewer laboratory tests in both the low cost and high cost tests groups. Similar studies elsewhere have found variable results, short and long term. ${ }^{5}$

Why does this matter? It is important to know that physician behavior in practice settings can be changed, and that the provision of fresh relevant knowledge about costs is one way to do so. A more complete list of clinician behavior change strategies (originally promulgated by John Eisenberg ${ }^{6}$ (see Table 1) includes: education, feedback, financial rewards, financial penalties, administrative changes and physician participation. Education alone is the least effective. Financial rewards work very well.

This approach worked in 1998 when cost control reasons were few. With the current national climate of incentives to actually contain costs, it should work even better in 2014 .

Corresponding Author: George D. Lundberg, MD; Stanford University, 3125600290104 Altura Vista, Los Gatos, CA 95032, USA (e-mail: Gdlundberg@gmail.com).

\section{REFERENCES}

1. Tilbert JC, Wynia MK, Sheeler RD, et al. Views of US physicians about controlling health care costs. JAMA. 2013;310(4):380-8.

2. Zhi M, Ding EL, Theisen-Toupal J, Whalen J, Arnaout R. The landscape of inappropriate laboratory testing: a 15-year metaanalysis. PLoS ONE. 2013;8(11):e78962. doi:10.1371/journal.pone.0078962.

3. Wertman BG, Sostrin SV, Pavlova Z, Lundberg GD. Why do physicians order laboratory tests? JAMA. 1980;243(20):2080-2.

4. Horn DM, Koplan KE, Senese MD, Orav EJ, Sequist TD. The impact of cost displays on primary care physician laboratory test ordering. J Gen Intern Med. 2014 doi:10.1007/s11606-013-2672-1.

5. Bates DW, Kuperman DJ, Jha A, et al. Does the computerized display of charges affect inpatient ancillary test utilization? Arch Intern Med. 1997; 157(21):2501-8

6. Lundberg GD. Changing physician behavior in ordering diagnostic tests JAMA. 1998;280(23):2036 